\title{
Artikel
}

\section{Schadevergoeding voor dummies}

\author{
Mr. H. de Hek*
}

\section{Inleiding}

Wie de jurisprudentie op het gebied van letselschade wil bijhouden, doet er de laatste jaren verstandig aan niet alleen de uitspraken van civiele rechters te volgen, maar ook die van strafrechters. In steeds meer strafzaken stellen benadeelden van een strafbaar feit als 'benadeelde partij' een vordering in tegen de verdachte. Waar schades die niet zijn veroorzaakt door een misdrijf buiten de sfeer van het verkeer meestal buiten rechte worden afgewikkeld, is dat anders voor schades die door een misdrijf zijn veroorzaakt. Daar zijn enkele redenen voor. Er is meestal geen (WAM-)verzekeraar die kan worden aangesproken tot vergoeding van de schade. Ook is de drempel voor een slachtoffer hoog om de veroorzaker van de schade zelf aan te spreken en met hem in onderhandeling te gaan. Bovendien zal de veroorzaker, zeker als het om een forse schade gaat, vaak geen verhaal bieden. Als de veroorzaker al een WA-verzekering heeft afgesloten, zal deze slechts zelden dekking bieden. De opzetclausule staat daaraan in de weg. De gang naar de strafrechter is dan een voor de hand liggende.

De procedure bij de strafrechter is allereerst laagdrempelig. De benadeelde kan zelf een voegingsformulier indienen en heeft dus geen bijstand nodig van een advocaat. Hij is ook geen griffierecht verschuldigd.

Bovendien is sinds 1 januari 2011, toen de Wet versterking positie slachtoffer in het strafproces ${ }^{1}$ werd inge-

* Mr. H. de Hek is senior-raadsheer bij het Gerechtshof Arnhem-Leeuwarden en redacteur van dit blad.

1. Wet van 17 december 2009 tot wijziging van het Wetboek van Strafvordering, het Wetboek van strafrecht en de Wet schadefonds geweldsmisdrijven ter versterking van de positie van het slachtoffer in het strafproces, Stb. 2010, 1

voerd, in artikel 36f $\mathrm{Sr}$ een voorschotregeling opgenomen. Deze regeling komt erop neer dat de Staat garandeert dat wanneer een schadevergoedingsmaatregel is opgelegd de bij die maatregel opgelegde schadevergoeding wordt uitbetaald aan het slachtoffer (niet zijnde een rechtspersoon). Sinds 1 januari 2016 geldt, op grond van artikel 2 van het Uitvoeringsbesluit voorschot schadevergoedingsmaatregel, ${ }^{2}$ de voorschotmaatregel zonder financiële bovengrens voor, kort gezegd, limitatief genoemde gewelds- en zedendelicten. Bij andere misdrijven is het maximum $€ 5.000$. Een benadeelde heeft er dan ook met het oog op het verhaal van zijn vordering een groot belang bij dat zijn schadeclaim door de strafrechter wordt behandeld. Hij heeft dan de meeste kans op vergoeding van zijn schade, ook omdat het Schadefonds geweldsmisdrijven slechts een tegemoetkoming in de schade biedt.

Er worden niet alleen steeds meer schadeclaims aan de strafrechter voorgelegd, er is een tendens zichtbaar dat de claims die bij de strafrechter worden ingediend ook steeds hoger en complexer worden. Deze tendens wordt versterkt door de toename van het antal gespecialiseerde (letselschade)advocaten en experts die zich toeleggen op het bijstaan van slachtoffers van misdrijven. ${ }^{3}$ Naar verwachting zal de vergoedbaarheid van affectieschade tot meer claims leiden. ${ }^{4}$

Besluit van 24 juli 2010, Stb. 2010, 311

3. Zie het in opdracht van het WODC in 2016 uitgebrachte rapport van UCALL (Utrecht Centre for Accountability and Liability Law), 'Civiel schadeverhaal via het strafproces', o.m. paragraaf 8.4.3.6.

4. Met de Wet van 11 april 2018 (Stb. 2018, 132) waarbij de affectieschade werd ingevoerd, is ook artikel 51 lid 2 Sv gewijzigd, waardoor de gerechtigden op affectieschade zich kunnen voegen in het strafproces. 


\section{Mogelijkheden en beperkingen}

Het indienen van een vordering bij de strafrechter heeft dus veel voordelen voor de benadeelde, vooral als het gaat om het verhaal van de vordering. Toch biedt de strafrechtelijke procedure geen onbegrensde mogelijkheden. Dat hangt samen met het feit dat de vordering van de benadeelde, een civiele vordering, moet worden ingediend in een strafrechtelijke procedure, op 'vreemd terrein' dus. Dat heeft zo zijn nadelen. Allereerst wordt de vordering bestreden, in sommige gevallen ook ingediend, en beoordeeld door juristen die niet altijd goed zijn ingevoerd in het civiele recht. Logisch, omdat zij zich vooral bezighouden met het strafrecht. Dat kan ertoe leiden dat vorderingen worden ingesteld met een ondeugdelijke juridische grondslag, tot een (veel) te hoog of juist een (veel) te laag bedrag, dat relevante verweren niet worden gevoerd, maar ook dat strafrechters 'koudwatervrees' lijken te hebben en proberen lastige civielrechtelijke vragen te omzeilen. ${ }^{5}$

De volgende beperking hangt ermee samen dat de civiele vordering in het strafproces accessoir is. ${ }^{6}$ Het is niet de bedoeling dat de civiele vordering het strafproces overheerst. Het gaat in het strafproces om het strafbare feit en om de verdachte: er moet worden vastgesteld of het tenlastegelegde feit bewezen kan worden, de verdachte strafbaar is en welke straf passend is. De civiele vordering 'lift mee' in dat proces. Dat komt uit in artikel 361 lid $3 \mathrm{~Sv}$ waarin is bepaald:

'Indien behandeling van de vordering van de benadeelde partij naar het oordeel van de rechtbank een onevenredige belasting van het strafgeding oplevert, kan de rechtbank op verzoek van de verdachte of op vordering van de officier van justitie dan wel ambtshalve bepalen dat de vordering geheel of ten dele niet ontvankelijk is en dat de benadeelde partij haar vordering of het deel van de vordering dat niet ontvankelijk is, slechts bij de burgerlijke rechter kan aanbrengen.'

Claassens $^{7}$ wijst erop dat in de praktijk steeds wordt geoordeeld dat het aanhouden van een strafzaak (uitsluitend) om meer klaarheid te krijgen over de civiele vordering, een onevenredige belasting van het strafgeding oplevert. Het oordeel van de feitenrechter over onevenredige belasting wordt door de Hoge Raad gezien als een feitelijk oordeel, dat in cassatie slechts op zijn begrijpelijkheid kan worden getoetst. ${ }^{8}$

Wanneer in aanmerking wordt genomen dat strafrechters te maken hebben met een grote zittingsdruk - poli-

5. Vgl. E.S. Engelhard, M.R. Hebly \& I. Van der Zalm, 'De shockschadevordering in het strafproces', TVP 2015/4, p. 87-96, die vaststellen dat ten aanzien van shockschadevorderingen - vorderingen die een ingewikkelde juridische afweging vergen - geregeld een niet-ontvankelijkverklaring wordt uitgesproken.

6. Zie J.C.C.M. Claassens, 'Complexe vorderingen in het strafproces', TLP 2017/4.

7. Claassens 2017

8. Vgl. Hoge Raad 4 maart 2014, ECLI:NL:HR:2014:476. tierechters worden bijvoorbeeld geacht een groot aantal zaken in een dagdeel af te handelen -, laat het zich raden dat een vordering van een benadeelde partij, zeker als het een complexe vordering betreft, niet altijd met veel enthousiasme wordt onthaald; ook die vordering moet dan nog behandeld worden in de toch al krap bemeten zittingstijd. Volgens Felix en Schildt leidt die krappe zittingstijd er geregeld toe dat de vordering van een benadeelde partij niet-ontvankelijk wordt verklaard. ${ }^{9}$

Verder is van belang dat de schadevergoedingsprocedure binnen het strafproces niet dezelfde processuele mogelijkheden biedt als een procedure voor de burgerlijke rechter. De benadeelde partij mag ter zitting wel stukken in het geding brengen ter onderbouwing en bewijs van zijn vordering, maar kan geen getuigen of deskundigen aanbrengen (artikel 334 lid 1 Sv). De Hoge $\operatorname{Raad}^{10}$ heeft beslist dat deze bepaling, gelet op de eisen van een eerlijk proces (vooral het beginsel van equality of arms), meebrengt dat ook de verdachte niet de bevoegdheid heeft getuigen of deskundigen aan te brengen. Dat betekent dat de strafrechtelijke procedure dus niet dezelfde waarborgen aan de procespartijen biedt als een gewone civiele procedure. Volgens de Hoge $\mathrm{Raad}^{11}$ wordt daarin voorzien door artikel 361 lid $3 \mathrm{~Sv}$. Deze bepaling moet in het licht van artikel 6 EVRM zo worden uitgelegd dat zij de strafrechter tot niet-ontvankelijkheidverklaring verplicht indien hij niet verzekerd acht dat beide partijen in voldoende mate in de gelegenheid zijn geweest om hun vordering/verweer te onderbouwen en om, voor zover nodig en mogelijk, bewijs te leveren, aldus de Hoge Raad.

Ten slotte kan de context van het strafproces de verdachte hinderen bij het voeren van verweer. Een bekennende verdachte zal een psychologische drempel ervaren om geharnast verweer te voeren; de rechter die over dat verweer moet oordelen, zal ook de strafmaat vaststellen en zal mogelijk bij een uitgebreid verweer tegen de vordering van de benadeelde partij de oprechtheid van de excuses van de verdachte in twijfel trekken, met alle gevolgen van dien voor de strafmaat. Een ontkennende verdachte heeft weer een ander probleem. Hij kan bij zijn verweer niet gemakkelijk gebruikmaken van informatie die in de strafrechtelijke veroordeling tegen hem pleit. Het verweer 'ik heb de portemonnee niet gestolen, maar er zat geen $€ 50$ in' is geen sterk strafrechtelijk verweer, hoewel het civielrechtelijk hout kan snijden.

De conclusie is dat de mogelijkheid om (complexe) civiele vorderingen in te dienen zijn grens vindt in wat het strafproces (en soms wellicht de strafrechter) aankan en in de waarborgen die het strafproces kan bieden aan de partijen in het civiele geschil waaraan het proces onderdak biedt. Daarbij ligt het voor de hand dat naarmate de vordering complexer is, de druk op het strafproces toeneemt en partijen meer behoefte zullen

9. I. Felix \& A. Schildt, 'Stelplicht, bewijslastverdeling en de civiele vordering van de benadeelde partij in het strafproces', NJB 2019/13, p. $850-857$.

10. Hoge Raad 13 december 2011, ECLI:NL:HR:2011:BQ0834

11. Hoge Raad 15 september 2006, ECLI:NL:HR:2006:AV2654. 
hebben aan de waarborgen die een civiele procedure wel, maar een strafproces niet kan bieden.

Gelet hierop is het overigens niet verwonderlijk dat de wetgever in het conceptwetsvoorstel Innovatiewet Strafvordering, dat onlangs in consultatie is gegeven, voorstelt om de behandeling van de vordering benadeelde partij in verband met een gewelds- of zedenbedrijf waarvan de behandeling een onevenredige belasting oplevert 'af te splitsen' van de strafzaak. ${ }^{12}$ De vordering wordt dan afzonderlijk van de oorspronkelijke strafzaak behandeld door een kamer van de rechtbank (of het gerechtshof). In deze procedure kunnen wel getuigen en deskundigen worden gehoord. In de memorie van toelichting wordt opgemerkt dat 'het in veel gevallen menselijk is dat een of meer rechters die ervaring hebben met het civiele recht bij de behandeling worden betrokken.' Opmerking verdient dat (om budgettaire redenen - volgens de memorie van toelichting gaat het al snel om forse bedragen per zaak en is niet in te schatten om hoeveel zaken het zal gaan, zodat de gevolgen van toepassing van de voorschotregeling op afgesplitste vorderingen niet goed in kaart te brengen zijn) de voorschotregeling niet van toepassing is op de afgesplitste vordering. ${ }^{13}$ Dat is weliswaar een tegenvaller voor de benadeelde partij, maar onder de huidige regeling kan de benadeelde partij die niet-ontvankelijk wordt verklaard ook geen aanspraak maken op de voorschotregeling.

\section{Het arrest van 28 mei 2019}

Het is tegen deze achtergrond dat de Hoge Raad op 28 mei 2019 een belangrijk arrest heeft gewezen. ${ }^{14}$ In het kopje van rechtspraak van de week wordt het arrest omschreven als een 'overzichtsarrest vordering b.p.'. Die typering is treffend. Het arrest biedt uitgebreide beschouwingen over de vordering benadeelde partij. Die beschouwingen - paragraaf 2 van het arrest met de titel 'Aan de beoordeling van het middel voorafgaande beschouwingen over de vordering van de benadeelde partij' - tellen 15 bladzijden, afgezien van het (eind)notenapparaat dat uit 51 voetnoten bestaat. De bespreking van het middel steekt daar, met een karige 4 bladzijden (grotendeels weergave van de beslissingen in de feitelijke instanties) nogal mager bij af. Je krijgt de indruk dat het min of meer bij toeval is dat juist deze zaak is uitgekozen om als casus te dienen voor het overzichtsarrest.

Opvallend is dat de kamer van de Hoge Raad die het arrest heeft gewezen uit vijf raadsheren bestaat, waarvan twee van de civiele kamer van de Hoge Raad. Van de drie strafrechters heeft er één een achtergrond als civiele rechter en raadsheer en een ander heeft in het verleden in publicaties zijn kennis van en interesse in de vordering benadeelde partij getoond.

12. De artikelen 561 e.v. van het voorstel.

13. Artikel 561a Sv (nieuw).

14. Hoge Raad 28 mei 2019, ECLI:NL:HR:2019:793.

\section{Het doel van het arrest}

Het zal duidelijk zijn dat de Hoge Raad niet zonder reden veel energie heeft gestoken in dit arrest. De Hoge Raad geeft in de inleiding van paragraaf 2 ook aan wat de reden is. De Hoge Raad zet in bij de bedoeling van de wetgever met de mogelijkheid tot het instellen van een vordering door benadeelde partijen. De wetgever wilde, in de woorden van de Hoge Raad, ${ }^{15}$ voorzien in een eenvoudige en laagdrempelige procedure die ertoe leidt dat personen die schade hebben geleden als gevolg van een strafbaar feit zo veel mogelijk schadeloos worden gesteld. De Hoge Raad wijst erop dat de strafrechter de vordering geheel of gedeeltelijk niet-ontvankelijk kan verklaren indien de vordering van de benadeelde partij een onevenredige belasting van het strafproces oplevert. De Hoge Raad stelt vervolgens vast dat het bieden van die eenvoudige en laagdrempelige procedure de strafrechter voor complexe afwegingen kan stellen, omdat hij ervoor moet zorgen dat daarbij het materiële civiele recht en de processuele regels en waarborgen die gelden voor de beoordeling van de vordering van de benadeelde partij in acht worden genomen, maar daarnaast ook moet oordelen over de in de strafzaak zelf aan de orde zijnde vragen. Tegen die achtergrond ziet de Hoge Raad aanleiding om 'aan de hand van zijn eerdere rechtspraak ten behoeve van de rechtspraktijk enige aandachtspunten te bespreken die bij de beoordeling van de benadeelde partij een rol kunnen spelen.'

De Hoge Raad voegt daaraan toe dat daarvoor temeer aanleiding bestaat vanwege de mogelijkheid om per 1 januari 2019 in het strafproces zogenaamde verplaatste schade te verhalen en aanspraak te maken op affectieschade. De inleiding sluit dan af met de overweging:

'Mede gelet op het grote belang dat benadeelde partijen erbij hebben op een eenvoudige wijze schadeloos gesteld te worden voor de schade die zij door een strafbaar feit hebben geleden, beoogt deze uiteenzetting ook te voorkomen dat de strafrechter vaker dan nodig gebruikmaakt van zijn bevoegdheid een benadeelde partij in haar vordering niet-ontvankelijk te verklaren omdat hij vindt dat de behandeling daarvan een onevenredige belasting van het strafgeding zou opleveren.'

Kort en goed komt het erop neer dat de Hoge Raad de rechtspraktijk, en zeker ook de strafrechters die steeds meer op hun bord krijgen, wil helpen om binnen de beperkingen van het strafproces te beslissen op vorderingen van benadeelde partijen. De Hoge Raad doet dat door 'aandachtspunten' te bespreken aan de hand van zijn eigen rechtspraak. Het doel van dit alles is 'mede' om te voorkomen dat vorderingen vaker dan nodig nietontvankelijk worden verklaard, want dat is gezien het grote belang van de benadeelde partij om op eenvoudige wijze schadeloos te worden gesteld niet de bedoeling. 
Met deze inleiding lijkt de Hoge Raad strafrechters te willen aanmoedigen om, in het belang van de benadeelde partij, een vordering niet te snel niet-ontvankelijk te verklaren en geeft hij de strafrechters ook een middel in handen om de vorderingen zelf af te doen, een arrest waarin de belangrijkste knelpunten netjes op een rij worden gezet. Mijn inschatting is, gebaseerd op de cursussen die ik aan strafrechters heb gegeven, dat die stimulans geen kwaad kan. Strafrechters maken zich zeker niet gemakkelijk van een vordering benadeelde partij af, maar hikken vaak wel aan tegen de zeker voor niet-civilisten ingewikkelde schadebegrotingsvragen die bij de beoordeling van zo'n vordering beantwoord moeten worden. Wanneer dan ook nog in aanmerking wordt genomen dat die vragen op korte termijn (uitspraaktermijn van twee weken) of onmiddellijk (bij een politierechterzitting) beantwoord moeten worden in een context van forse werk- en zittingsdruk, is het helemaal niet zo vreemd dat een vordering vaker dan nodig zou zijn niet-ontvankelijk wordt verklaard, met alle nadelige gevolgen voor de benadeelde partij van dien. Een module 'schadevergoeding voor dummies' kan dan goede diensten bewijzen.

\section{Schadevergoeding voor dummies}

In het vervolg van het arrest ${ }^{16}$ citeert de Hoge Raad pagina's lang alle bepalingen die van belang zijn bij de beoordeling van de vordering benadeelde partij. De Hoge Raad haalt de relevante bepalingen uit het Wetboek van Strafvordering en het Wetboek van Strafrecht aan, maar ook een aantal bepalingen ${ }^{17}$ uit titel 10 van boek 6 en artikel 162 van het Burgerlijk Wetboek en enkele bepalingen uit het Wetboek van Burgerlijke Rechtsvordering. ${ }^{18}$

Daarna ${ }^{19}$ gaat de Hoge Raad an de hand van artikel 51f lid $1 \mathrm{~S}$ en 362 lid $2 \mathrm{~Sv}$ in op de vraag wanneer sprake is van rechtstreekse schade in de zin van die bepalingen. Relevant, omdat op grond van deze bepalingen alleen het slachtoffer dat 'rechtstreeks schade' heeft geleden zich als benadeelde partij kan voegen in de strafzaak. Voldoende is dat tussen het bewezenverklaarde handelen van de verdachte en de schade 'voldoende verband' bestaat. Of daarvan sprake is, is afhankelijk van de concrete omstandigheden van het geval. Daarbij is, overweegt de Hoge Raad, niet vereist dat de benadeelde partij getroffen is in een belang dat door de overtreden strafbepaling rechtstreeks wordt beschermd ${ }^{20}$ Dat sluit aan bij de uitwerking van het relativiteitsvereiste (artikel 6:163 BW) in het civiele recht, waar ook niet de strenge

\footnotetext{
6. R.o. 2.2

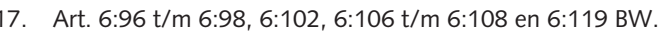

18. Art. $139,149,150,236 \mathrm{t} / \mathrm{m} 239$ en $241 \mathrm{Rv}$

19. R.o. 2.3.1 en 2.3.2.

20. De Hoge Raad verwijst naar zijn arrest van 5 juli 2016, ECLI:NL:HR: 2016:1522
}

eis wordt gesteld dat de gelaedeerde moet zijn getroffen in een belang dat rechtstreeks wordt beschermd door een geschonden geschreven norm (zoals een strafbepaling is). ${ }^{21}$ De Hoge Raad geeft aan de hand van zijn uitspraken een aantal voorbeelden van gevallen van rechtstreekse schade.

$\mathrm{Na}$ het begrip rechtstreekse schade gaat de Hoge Raad in op het begrip schade..$^{22}$ De Hoge Raad volgt de systematiek van titel 10 van boek $6 \mathrm{BW}$ door achtereenvolgens stil te staan bij de kernbepaling van artikel 6:95 $\mathrm{BW}$, de verschillende categorieën vermogensschade van artikel 6:96 BW, ander nadeel (artikel 6:106 BW), affectieschade en verplaatste schade, waarbij de Hoge Raad vooral verwijst naar artikel $51 \mathrm{f}$ lid $2 \mathrm{~Sv}$ dat het sinds 1 januari 2019 mogelijk maakt dat ook derden zich voor hun verplaatste schade (artikel 6:107 lid 1 onder a BW) in de strafprocedure voegen en ten slotte wettelijke rente en proceskosten.

De overwegingen over de verschillende schadecategorieën bieden niets nieuws - dat hoeft, gezien de inleiding van het arrest, ook niet te verwonderen -, maar bieden wel een handzaam overzicht van de hoofdlijnen van de rechtspraak van de Hoge Raad over schadebegroting.

Aan de orde komen de wijze van schadebegroting (in beginsel concreet, maar soms abstract, bijvoorbeeld bij zaakschade), de gronden voor toekenning van immateriele schade (waarbij het EBI-arrest ${ }^{23}$ wordt samengevat) en de vereisten voor toekenning van een shockschadeclaim. Steeds verwijst de Hoge Raad naar de relevante vindplaatsen. De Hoge Raad wijst op de mogelijkheid van vergoeding van affectieschade en is zo attent om daarbij op te merken dat affectieschade op grond van het overgangsrecht alleen kan worden toegekend voor schadeveroorzakende gebeurtenissen die plaatsvinden na 1 januari 2019.

De overwegingen over de wettelijke rente betreffen vooral de formele kant; wettelijke rente kan alleen worden toegewezen wanneer dat is gevorderd. Als dat niet is gebeurd, staat dat er weer niet aan in de weg dat de rechter bepaalt dat het bedrag van de schadevergoedingsmaatregel moet worden vermeerderd met de wettelijke rente.

De Hoge Raad besteedt relatief veel aandacht aan de proceskosten. Hij wijst op al wat oudere rechtspraak ${ }^{24}$ waaruit volgt dat de strafrechter bij de begroting van de proceskosten dezelfde maatstaf hanteert als de civiele rechter. De Hoge Raad legt vervolgens uit hoe in het civiele recht de proceskosten doorgaans worden begroot (volgens het zogenaamde liquidatietarief, waarbij de Hoge Raad ook nog aangeeft waar dat is te vinden) en legt uit hoe het systeem werkt als er met toevoeging wordt geprocedeerd.
21. Vgl., naast heel veel meer, voor een beknopte uiteenzetting A.S. Hartkamp \& C.H. Sieburgh, Asser 6-IV De verbintenis uit de wet, Deventer: Wolters Kluwer 2015, nr. 129 e.v.

22. R.o. $2.4 \mathrm{t} / \mathrm{m} 2.4 .8$.

23. Hoge Raad 15 maart 2019, ECLI:NL:HR:2019:376.

24. Hoge Raad 29 mei 2001, ECLI:NL:HR:2001:AB1819. 
Opmerkelijk is dat de Hoge Raad tussen de bedrijven door uitlegt hoe het met hoofdelijkheid zit. Dat dat anders werkt bij de begroting van schade van een benadeelde partij dan bij de bepaling van het bedrag van het wederrechtelijk verkregen voordeel (36e lid $7 \mathrm{Sr}$ ) en dat en hoe een hoofdelijke veroordeling in het dictum tot uitdrukking moet komen.

Deze paragraaf van de Hoge Raad leest echt als een cursus schadevergoeding voor dummies. De Hoge Raad lijkt het de lezers, waarbij hij vooral het oog lijkt te hebben op de strafrechters (en secretarissen) onder hen, zo gemakkelijk mogelijk te willen maken en kiest daarbij een praktische insteek; tal van technische vragen, die wanneer je ze als rechter moet uitzoeken veel tijd en hoofdbrekens bevatten - zoals vanaf wanneer kan ik affectieschade toekennen en hoe zit het met een proceskostenveroordeling - worden op detailniveau behandeld. Het arrest maakt de behandeling van een vordering benadeelde partij wellicht niet leuker voor een strafrechter, maar zeker wel gemakkelijker!

\section{Stelplicht en bewijslast}

Aan het slot van zijn beschouwingen gaat de Hoge Raad onder het tussenkopje 'Beoordeling en beslissing rechter'25 in op stelplicht en bewijslast. Onlangs zijn twee strafrechters ingegaan op stelplicht en bewijslast bij de behandeling van een civiele procedure in het strafproces. ${ }^{26}$ Hun conclusie is dat voor het begroten van de schade de regels van stelplicht en bewijslast door de Hoge Raad in belangrijke mate zijn gerelativeerd. Het past bij de aard van de voegingsprocedure te aanvaarden dat het in beginsel aan de benadeelde is om zijn vordering zodanig te onderbouwen dat deze in voldoende mate komt vast te staan. De benadeelde partij heeft een onderbouwingsplicht. Het daarnaast vasthouden aan de civiele regels voor stelplicht en bewijslast lijkt niet zinvol, menen zij. Zij gaan daarmee in tegen de heersende lijn in de literatuur ${ }^{27}$ en, wat belangrijker is, tegen rechtspraak van de Hoge Raad. ${ }^{28}$

De Hoge Raad volgt hen niet en handhaaft zijn eerder ingezette lijn. Voor de toewijsbaarheid van de vordering van de benadeelde partij gelden niet de bewijs(minimum)regels van het Wetboek van Strafvordering maar de regels van stelplicht en bewijslastverdeling in civiele zaken, aldus de Hoge Raad. De Hoge Raad zet dan uiteen hoe dat in de context van het strafproces uitpakt.

De Hoge Raad stelt voorop dat de benadeelde partij in beginsel de feiten en omstandigheden zal moeten stellen - en bij betwisting bewijzen - die tot toewijzing van de

25. R.o. 2.8.1-2.8.7.

26. Felix \& Schild 2019

27. Vgl. W.H. Vellinga, 'De benadeelde partij in het strafproces vanuit civielrechtelijk perspectief bezien', VR 2001/4 en J. Candido, 'Civiel bewijsrecht toepasselijk op de vordering benadeelde partij?', NJB 2012/824, p. 938-940.

28. Vgl. Hoge Raad 3 oktober 2006, ECLI:NL:HR:2006:AW3559 en 14 februari 2012, ECLI:NL:HR:2012:BU8755. vordering kunnen leiden. Dat zullen in de strafzaak vooral de feiten en omstandigheden zijn die niet uit het strafproces zijn af te leiden, veelal de feiten en omstandigheden betreffende aard en omvang van de schade.

Als de vordering wordt betwist, zal de rechter aan de hand van de onderbouwing van de stellingen over en weer moeten beoordelen of de feiten en omstandigheden die tot toewijzing van de vordering kunnen leiden in voldoende mate zijn komen vast te staan, aldus de Hoge Raad, die tot zover het civiele stelsel volgt.

De vraag rijst wat er gebeurt wanneer de verdachte de vordering niet (gemotiveerd) betwist. Op grond van artikel $149 \mathrm{Rv}$ zal de rechter uitgaan van de juistheid van de aan de vordering ten grondslag gelegde feiten en zal hij de vordering moeten toewijzen. Dat is anders wanneer de vordering hem onrechtmatig of ongegrond voorkomt, aldus de Hoge Raad. Die maatstaf - onrechtmatig of ongegrond - wordt gebruikt in artikel $139 \mathrm{Rv}$ over de beoordeling van een vordering in een verstekprocedure. De Hoge Raad voegt daaraan toe dat de strafrechter een niet (voldoende) weersproken vordering ook niet toewijst wanneer zich 'het geval voordoet maarin de rechter door de beperkingen van het strafproces niet verzekerd acht dat beide partijen in voldoende mate in de gelegenheid zijn gemeest hun stellingen en onderboumingen met betrekking tot de toemijsbaarheid genoegzaam naar voren te brengen. In laatstgenoemd geval ligt het in de rede dat de benadeelde partij niet-ontvankelijk is en zij haar vordering bij de burgerlijke rechter kan aanbrengen.'

Dat is anders dan in het proces voor de burgerlijke rechter, waar een onvoldoende weersproken vordering wordt toegewezen. Op deze manier komt de Hoge Raad tegemoet aan de eerder in het arrest door hem gesignaleerde beperkingen van het strafproces. Voor de verdachte - tegelijkertijd gedaagde ten aanzien van de civiele vordering - betekent dit, anders dan in de civiele procedure, dat het doek niet meteen valt wanneer hij onvoldoende verweer voert. Als dat het gevolg is van de beperkingen van het strafproces, wordt de vordering niet toegewezen. De vraag is wanneer daarvan sprake is. In elk geval wanneer de verdachte meer tijd nodig heeft om te reageren op de vordering dan hem in het strafproces kan worden geboden. Dat zal bijvoorbeeld het geval zijn als de benadeelde partij pas kort voor de zitting een uitvoerig onderbouwde vordering instelt waardoor de verdachte geen gelegenheid heeft gehad adequaat verweer te voeren. Dat een verdachte ontkent, betekent niet per definitie dat hij geen verweer kan voeren tegen de omvang van de vordering. Alleen wanneer voor het voeren van verweer 'daderinformatie' noodzakelijk is die niet uit het strafdossier blijkt, komt de 'rol' van verdachte in conflict met die van 'dader'. In die situatie is verdedigbaar dat het niet (gemotiveerd) betwisten van de vordering het gevolg is van de beperkingen van het strafproces. Voor veel onderdelen van de vordering zal die beperking niet gelden. Het valt immers niet in te zien waarom een ontkennende verdachte van een zware mishandeling geen verweer kan voeren tegen de omvang van de schade vanwege ziektekosten of de schade vanwege verlies verdienvermogen. 
Wanneer de eiser in een civiele procedure zijn vordering niet goed voldoende onderbouwt of wanneer de vordering wel goed is onderbouwd maar gemotiveerd verweer wordt gevoerd, of de (betwiste) feiten en omstandigheden die ten grondslag liggen aan zijn vordering niet kan bewijzen, wordt de vordering afgewezen. In het strafproces ligt dat anders. De Hoge Raad:

'Slechts in gevallen waarin de niet-toewijsbaarheid niet volgt uit de beperkingen van het strafproces, de benadeelde partij genoegzaam in de gelegenheid is geweest haar vordering te onderbouwen en de ongegrondheid van die vordering in voldoende mate is komen vast te staan, kan de rechter ervoor kiezen de vordering af te wijzen.'

Niet alleen de verdachte, ook de benadeelde partij wordt dus beschermd door het feit dat de vordering is ingesteld in een strafrechtelijke procedure. Een onvoldoende onderbouwing of onvoldoende bewijs van de vordering leidt niet steeds tot afwijzing van de vordering. Dat is geen vrijbrief voor het onvoldoende onderbouwen van een vordering; als de onvoldoende onderbouwing niet het gevolg is van de beperkingen van het strafproces, kan de rechter de vordering wel afwijzen. Opvallend zijn de woorden 'kan de rechter ervoor kiezen' de vordering af te wijzen. De civiele rechter heeft die discretionaire bevoegdheid niet: een vordering die onvoldoende onderbouwd is, moet worden afgewezen.

De conclusie is dat de civiele regels van stelplicht en bewijslastverdeling gelden, maar dat de 'harde kanten' ervan worden verzacht, doordat de sanctie die in het civiele procesrecht geldt voor het onvoldoende onderbouwen of betwisten van een vordering - afwijzen respectievelijk toewijzen van de vordering - in de strafprocedure niet onverkort geldt.

De Hoge Raad vervolgt dit onderwerp met erop te wijzen dat de strafrechter een vordering ook mag splitsen in een deel dat kan worden toe- of afgewezen en in een deel dat niet-ontvankelijk wordt verklaard. ${ }^{29}$ Dat had de Hoge Raad al meerdere keren uitgemaakt. In het arrest wordt ook naar deze rechtspraak verwezen.

De feitenrechter krijgt ook nog wat wenken over de motivering van zijn oordeel. Dat moet begrijpelijk zijn, waarbij geldt dat naarmate de vordering uitvoeriger en specifieker wordt weersproken, de motivering van de toewijzing van de vordering meer aandacht zal vragen. ${ }^{30}$ Gesneden koek voor de civiele rechter, maar gelet op de soms zeer beknopte motivering van de toewijzing van complexe vorderingen door de strafrechter, de moeite van een vingerwijzing door de Hoge Raad wel waard.

De paragraaf sluit af met een paar algemene overwegingen over de begroting van immateriële schade en de mogelijkheid van schatting. Over die mogelijkheid overweegt de Hoge Raad:
'Indien de omvang van de schade zonder nader onderzoek dat een onevenredige vertraging van het strafgeding zou opleveren, niet nauwkeurig kan worden vastgesteld, kan die omvang in veel gevallen worden geschat (art. 6:97 BW). De rechter dient in zijn motivering van die schatting zoveel mogelijk aan te sluiten bij de vaststaande feiten.'

Helemaal duidelijk is deze overweging niet. Bedoelt de Hoge Raad de feitenrechter te attenderen op de mogelijkheid van schatting of wil hij zeggen dat de mogelijkheid van schatting in een procedure voor de strafrechter ruimer is dan in een procedure voor de civiele rechter? Die laatste lezing lijkt niet waarschijnlijk. Wanneer op de vordering van de benadeelde partij de regels van het materiële civiele recht en die van stelplicht en bewijslastverdeling van toepassing zijn, ligt het niet voor de hand dat artikel 6:97 BW in het strafproces anders moet worden uitgelegd dan in het civiele proces.

\section{Ten slotte}

De Hoge Raad heeft de rechtspraktijk echt een dienst bewezen met dit arrest. Niet alleen de strafrechtspraktijk heeft er baat bij, juist ook de letselschadepraktijk. Zoals in de inleiding is aangegeven, worden steeds meer letselschadeclaims bij de strafrechter ingediend. Het arrest maakt het strafrechters veel gemakkelijker om in elk geval veel voorkomende vorderingen, maar ook de wat ingewikkelder vorderingen, inhoudelijk te beoordelen en verhoogt op die manier de drempel om uit onbekendheid met het onderwerp de vordering maar nietontvankelijk te verklaren. Dat maakt het nog aantrekkelijker om een vordering in het strafproces in te dienen. Voor slachtoffers van delicten is dat winst.

Los van deze effecten op macroniveau geldt dat het arrest ook de gemiddelde letselschadejurist het nodige te bieden heeft. Voor diverse schadeposten wordt de stand van de rechtspraak netjes op een rij gezet. Wie het arrest nauwkeurig doorleest, bespaart zich de eerstvolgende actualiteitencursus. 